\title{
Effects of apelin and leptin on renal functions following renal ischemia/reperfusion: An experimental study
}

\author{
TAMER SAGIROGLU ${ }^{1}$, NESE TORUN $^{2}$, MEHMET YAGCI $^{3}$, TÜLIN YALTA $^{4}$, \\ GÖNÜL SAGIROGLU ${ }^{5}$ and SERHAT OGUZ ${ }^{1}$
}

\author{
Departments of ${ }^{1}$ General Surgery, and ${ }^{2}$ Nuclear Medicine, Faculty of Medicine, Trakya University, Edirne 22030; \\ ${ }^{3}$ Hakkari State Hospital, Hakkari; Departments of ${ }^{4}$ Pathology, and ${ }^{5}$ Anesthesiology and Reanimation, \\ Faculty of Medicine, Trakya University, Edirne 22030, Turkey
}

Received December 21, 2011; Accepted January 20, 2012

DOI: 10.3892/etm.2012.499

\begin{abstract}
The present study aimed to investigate the effects of apelin and leptin on renal functions following renal ischemia/ reperfusion (I/R). A total of 32 rats were divided into four groups. The control group was not induced with ischemia, but was administered normal saline intraperitoneally. Normal saline, apelin and leptin were administered intraperitoneally to the $I / R$, ischemia/reperfusion and apelin (I/R+A) and ischemia/reperfusion and leptin $(\mathrm{I} / \mathrm{R}+\mathrm{L})$ groups, in turn for three days prior to the surgical procedure. Blood and urine samples were obtained after $24 \mathrm{~h}$ of reperfusion, and scintigraphic examination was performed. Renal damage was evaluated histopathologically. Urea levels of the I/R+L and $\mathrm{I} / \mathrm{R}+\mathrm{A}$ groups were comparable, but were higher compared to that of the control group. The I/R group had the highest urea levels (control, 27 $\pm 2 ; \mathrm{I} / \mathrm{R}, 120 \pm 15 ; \mathrm{I} / \mathrm{R}+\mathrm{A}, 75 \pm 10 ; \mathrm{I} / \mathrm{R}+\mathrm{L}$, $80 \pm 11 ; \mathrm{p}<0.001)$. Creatinine levels were higher in all three ischemic groups compared to the control group. Glomerular filtration rate values of the $\mathrm{I} / \mathrm{R}+\mathrm{A}$ and $\mathrm{I} / \mathrm{R}+\mathrm{L}$ groups were not significantly, but numerically higher compared to that of the I/R group. No pathological damage was observed in any of the animals in the control group. In the I/R group, two animals had moderate and six had severe renal damage, while three had moderate and one had severe renal damage in the $\mathrm{I} / \mathrm{R}+\mathrm{L}$ group. In the $\mathrm{I} / \mathrm{R}+\mathrm{A}$ group, moderate renal damage was found in one animal, while none had severe renal damage. This study demonstrates the functional and histopathological protective effects of leptin and apelin against renal I/R injury.
\end{abstract}

\section{Introduction}

Ischemia results from obstruction of the vessels supplying blood to the tissues due to a number of reasons, and leads

Correspondence to: Dr Tamer Sagiroglu, Department of General Surgery, Faculty of Medicine, Trakya University, Edirne 22030, Turkey

E-mail: tamersagiroglu@gmail.com

Key words: apelin, leptin, renal ischemia/reperfusion to deficient tissue nutrition. If this occurs blood flow should be restored (reperfusion) via medicines or mechanical interventions to prevent ischemia-related cell and tissue damage. Ischemia-related damage can either be reversible or irreversible. A series of complex events that occur during reperfusion can occasionally cause greater damage than the ischemia itself (1). Renal ischemia/reperfusion (I/R) injury may occur due to systemic hypotension, hypovolemic shock, cardiac arrest, renovascular surgery and aortic clamping. The severity of the damage is increased with the duration of ischemia. As a result, different clinical entities, ranging from prerenal azotemia without marked tissue damage, to severe acute renal failure (ARF) due to tubular or cortical necrosis, may occur (2). Despite advances in critical care medicine, ARF remains a clinical problem, as it is a significant cause of morbidity and mortality. A number of pharmacological approaches have been investigated for the treatment of renal I/R injury. Substances including, novel antioxidants and antioxidant enzyme mimetics, nitric oxide and nitric oxide synthase inhibitors, erythropoietin (EPO), peroxisome-proliferator activated receptor agonists, inhibitors of poly (ADP-ribose) polymerase, carbon monoxide-releasing molecules, statins and adenosine, have been investigated for their efficacy against renal I/R injury and ischemic ARF in experimental studies (2). Although a number of promising pharmacological agents have been developed and demonstrated to be beneficial in experimental studies, the majority of clinical studies have yielded unsuccessful results. For these reasons, the search for new pharmacological agents for the treatment of renal I/R injury is ongoing, and studies in this field continue to attract attention (2). A number of substances have become the subject of studies due to their effects on the mechanisms involved in the pathophysiology of I/R injury.

Leptin is a hormone that is synthesized primarily by adipocytes and is found in the systemic circulation. It mainly affects body mass index by controlling food intake and energy expenditure (3). In vitro studies have demonstrated that leptin has marked mitogenic effects on endothelial and glomerular cells $(4,5)$. Moreover, leptin may affect the synthesis of nitric oxide through the activation of nitric oxide synthase (6). Studies employing a rat model of intestinal I/R injury have reported that leptin demonstrates a time-dependent response to 
acute inflammatory stimuli and acts as an anti-inflammatory cytokine $(7,8)$.

Apelin is a newly identified adipokine, which is synthesized in a number of tissues, including the gastrointestinal system, brain, kidney and liver. Apelin primarily affects the cardiovascular system. In vivo studies have demonstrated that apelin also has an endothelium-dependent vasodilator effect, in addition to its regulatory effects on arterial blood pressure (9).

The present study aimed to demonstrate the favorable and unfavorable effects of two adipokines, apelin and leptin, on renal functions following renal I/R.

\section{Materials and methods}

Study design. The present study was conducted in accordance with the Guidelines for the Care and Use of Experimental Animals established by the local committee on animal research ethics of the University. The committee approved the study design. A total of 32 male Sprague-Dawley rats aged between 6 and 8 weeks and weighing $280 \pm 20 \mathrm{~g}$ were used. Using a computer generated table of random numbers, rats were assigned to one of the following four groups, each containing eight animals: i) control group, administered normal saline solution intraperitoneally and subjected to aorta mobilization without any clamping of the aorta; ii) ischemia/reperfusion (I/R) group, administered normal saline solution intraperitoneally and induced with ischemia by clamping of the aorta and reperfusion; iii) ischemia/reperfusion and apelin (I/R+A) group, administered apelin intraperitoneally and induced with ischemia by clamping of the aorta and reperfusion; iv) ischemia/reperfusion and leptin $(\mathrm{I} / \mathrm{R}+\mathrm{L})$ group, administered leptin intraperitoneally and induced with ischemia by clamping of the aorta and reperfusion.

All animals were maintained under a controlled temperature $\left(22 \pm 2^{\circ} \mathrm{C}\right)$ and relative humidity of $55 \pm 15 \%$ under $12 \mathrm{~h}$ light/dark cycles. All animals were fed with chow and tap water ad libitum throughout the acclimatization and study periods.

Chemicals and reagents. Apelin-13 (200 $\mu \mathrm{g} /$ flacon; Apelin ${ }^{\circledR}$, Phoenix Pharmaceuticals Inc., Belmont, CA, USA) and leptin $\left(200 \mu \mathrm{g} /\right.$ flacon; Leptin ${ }^{\circledR}$, Phoenix Pharmaceuticals Inc., Belmont, CA, USA) were commercially purchased. The I/R+A group was administered apelin intraperitoneally at a dose of $1.5 \mu \mathrm{g} / \mathrm{kg}$. The $\mathrm{I} / \mathrm{R}+\mathrm{L}$ group was administered leptin intraperitoneally at a dose of $100 \mu \mathrm{g} / \mathrm{kg}$. Apelin and leptin were administered for three consecutive days prior to the surgical procedure. The control and I/R groups were administered normal saline solution intraperitoneally $(10,11)$.

Surgical procedure. Following a night of fasting, each animal was anesthetized with intraperitoneal xylazine $(5 \mathrm{mg} / \mathrm{kg}$ ) and ketamine hydrochloride $(30 \mathrm{mg} / \mathrm{kg})$. The abdomen was shaved and cleaned with povidone-iodine solution. Using a sterile technique, all animals underwent a laparotomy through a $3-\mathrm{cm}$ midline incision. The aorta and visceral arteries were exposed. The control group underwent suprarenal aorta mobilization without clamping of the aorta.

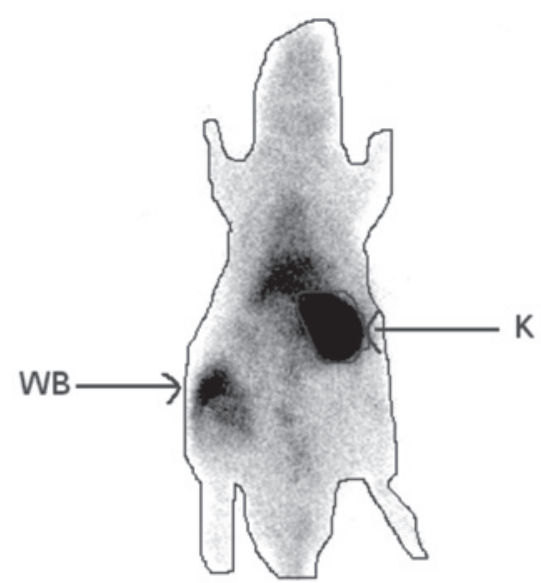

Figure 1. Regions of interest were drawn around the whole body to represent the total injected dose, and around the kidney to represent the renal function on $99 \mathrm{mTc}$ dimercaptosuccinic acid images. WB, whole body; K, kidney.

In the $\mathrm{I} / \mathrm{R}, \mathrm{I} / \mathrm{R}+\mathrm{A}$ and $\mathrm{I} / \mathrm{R}+\mathrm{L}$ groups, the suprarenal aorta was clamped with an atraumatic microvascular bulldog clamp. Ischemia was confirmed via visual inspection of the kidneys. The clamp remained in place for $40 \mathrm{~min}$. A total of $5 \mathrm{~min}$ prior to removal of the clamp, a right nephrectomy was performed. The midline incision was closed, and the rats were immediately returned to their cages for recovery.

Metabolic cage and biochemical assessment. Following the induction of ischemia, the animals were placed into individual metabolic cages for $24 \mathrm{~h}$. Urine samples, which were free of food and feces, were collected in graduated cylinders. Urine volume, urea, creatinine, osmolality, and glomerular filtration rate (GFR) were assessed during the 24th $\mathrm{h}$ of reperfusion. Blood samples were collected for measurements of serum blood urea nitrogen (BUN), creatinine, alanine transaminase (ALT), aspartate transaminase (AST) and $\gamma$-glutamyl transpeptidase (GGT).

Scintigraphic examination. A 99mTc dimercaptosuccinic acid (DMSA) scintigraphy was performed during the 24 th $\mathrm{h}$ of reperfusion. Imaging was performed, $2 \mathrm{~h}$ after the intravenous injection of $1 \mathrm{mCi} 99 \mathrm{mTc}$ DMSA via a $24 \mathrm{~F}$ catheter placed in the tail vein under general anesthesia. A total of $2 \mathrm{~h}$ after $99 \mathrm{mTc}$ DMSA was administered, whole-body images were acquired for $300 \mathrm{sec}$ (matrix, 512 x 512; zoom factor, 1.55) in the posterior projection using a single-head $\gamma$-camera equipped with a low energy all-purpose collimator. For semi-quantitative evaluation, regions of interest (ROIs) were drawn around the whole body to represent the total injected dose, and around the kidney to represent the renal function (Fig. 1). Background activity was measured using a ROI, which was drawn over a region outside of the body contour. The single kidney DMSA uptake (\%) was calculated using the following formula (12): DMSA uptake $(\%)=100 \mathrm{x}$ (kidney/whole body).

Histopathological examination. Harvested kidneys were fixed in $10 \%$ formalin for $24 \mathrm{~h}$, then routinely processed and 
Table I. Laboratory analysis of the blood samples obtained from the study groups.

\begin{tabular}{|c|c|c|c|c|c|}
\hline & Control & Ischemia/reperfusion & $\begin{array}{c}\text { Ischemia/reperfusion } \\
+ \text { leptin }\end{array}$ & $\begin{array}{c}\text { Ischemia/reperfusion } \\
+ \text { apelin }\end{array}$ & P-value \\
\hline Urea (mg/dl) & $27.00 \pm 7.33^{\mathrm{b}-\mathrm{d}}$ & $120.75 \pm 15.56^{\mathrm{a}, \mathrm{c}, \mathrm{d}}$ & $80.00 \pm 11.81^{\mathrm{a}, \mathrm{b}}$ & $75.50 \pm 10.84^{\mathrm{a}, \mathrm{b}}$ & $<0.001$ \\
\hline Creatinine (mg/dl) & $0.35 \pm 0.06^{\mathrm{b}-\mathrm{d}}$ & $1.79 \pm 0.49^{\mathrm{a}}$ & $1.36 \pm 0.45^{\mathrm{a}}$ & $1.40 \pm 0.38^{\mathrm{a}}$ & $<0.001$ \\
\hline Total protein $(\mathrm{g} / \mathrm{dl})$ & $6.29 \pm 0.27^{\mathrm{c}, \mathrm{d}}$ & $5.90 \pm 0.33$ & $5.86 \pm 0.30^{\mathrm{a}}$ & $5.86 \pm 0.23^{\mathrm{a}}$ & 0.014 \\
\hline Albumin $(\mathrm{g} / \mathrm{dl})$ & $2.81 \pm 0.59$ & $2.93 \pm 0.22$ & $2.96 \pm 0.19$ & $3.03 \pm 0.14$ & 0.640 \\
\hline $\operatorname{AST}(\mathrm{U} / \mathrm{l})$ & $134.75 \pm 53.28^{\mathrm{b}}$ & $274.50 \pm 50.66^{\mathrm{a}, \mathrm{c}, \mathrm{d}}$ & $189.25 \pm 18.88^{\mathrm{b}}$ & $190.75 \pm 19.39^{b}$ & $<0.001$ \\
\hline ALT (U/l) & $60.13 \pm 16.55^{\mathrm{b}-\mathrm{d}}$ & $143.75 \pm 24.51^{\mathrm{a}}$ & $106.50 \pm 27.54^{\mathrm{a}}$ & $106.62 \pm 24.50^{\mathrm{a}}$ & $<0.001$ \\
\hline GGT (U/1) & $559.00 \pm 46.75^{\mathrm{b}-\mathrm{d}}$ & $1,112.25 \pm 125.45^{\mathrm{a}, \mathrm{c}, \mathrm{d}}$ & $838.88 \pm 138.46^{\mathrm{a}, \mathrm{b}}$ & $842.75 \pm 135.10^{\mathrm{a}, \mathrm{b}}$ & $<0.001$ \\
\hline Sodium (mmol/dl) & $136.38 \pm 4.00^{\mathrm{b}}$ & $147.25 \pm 6.50^{\mathrm{a}}$ & $142.13 \pm 3.04$ & $142.38 \pm 2.00$ & $<0.001$ \\
\hline Potassium (mmol/dl) & $4.94 \pm 0.50^{\mathrm{b}}$ & $5.99 \pm 0.38^{\mathrm{a}, \mathrm{c}, \mathrm{d}}$ & $5.25 \pm 0.39^{\mathrm{b}}$ & $5.13 \pm 0.34^{\mathrm{b}}$ & $<0.001$ \\
\hline Chloride (mmol/dl) & $104.00 \pm 3.16$ & $102.38 \pm 3.29$ & $102.25 \pm 2.92$ & $101.50 \pm 3.96$ & 0.511 \\
\hline
\end{tabular}

AST, aspartate transaminase; ALT, alanine transaminase; GGT, $\gamma$-glutamyl transpeptidase. For each group, $\mathrm{n}=8$. Values are presented as mean \pm SD ${ }^{a}$ Different from the control group, ${ }^{b}$ Different from the ischemia/reperfusion group, ${ }^{\mathrm{C}}$ Different from the ischemia/reperfusion + leptin group, ${ }^{\mathrm{d}}$ Different from the ischemia/reperfusion + apelin group. P-value in bold print indicates a significant difference.

embedded in paraffin. Sections $(5 \mu \mathrm{m})$ were cut from paraffin blocks and stained with hematoxylin and eosin (H\&E). Slides were then examined under a light microscope (Nikon E600W, Japan) Each slide was evaluated by an expert investigator blinded to the experiment and data. Slides were examined for tubular cell swelling, interstitial edema, medullary congestion, tubular dilatation and necrosis. Renal damage was graded as none, mild, moderate or severe (13).

Statistical analysis. Statistical analysis was conducted using the Statistical Package for the Social Sciences (SPSS) for Windows (version 15.0; SPSS Inc., Chicago, IL, USA). Descriptive statistics (mean, standard deviation, minimum, maximum and median) were presented for numerical variables. For independent groups, a one-way analysis of variance (ANOVA) was used for multiple comparisons when the data was normally distributed, while the Kruskal-Wallis test was used when the data were not normally distributed. In the case of significant differences between groups, the Bonferroni correction and Tukey's tests were used when the data was normally distributed. Otherwise, a post hoc analysis with the Bonferroni correction and Mann-Whitney U test was carried out. Categorical variables were compared using the Monte Carlo method when the Chi-square assumption was not met. $\mathrm{P}<0.05$ was considered to indicate a statistically significant difference.

\section{Results}

There was no significant difference between the study groups with respect to albumin and chloride levels, however there were significant differences in terms of urea, creatinine, total protein, AST, ALT, GGT, sodium and potassium levels. Laboratory analysis of the blood samples obtained from the study groups are summarized in Table I. One animal in the control group and one animal in the $\mathrm{I} / \mathrm{R}+\mathrm{L}$ group died after blood and urine samples were obtained and scintigraphic examinations were performed.

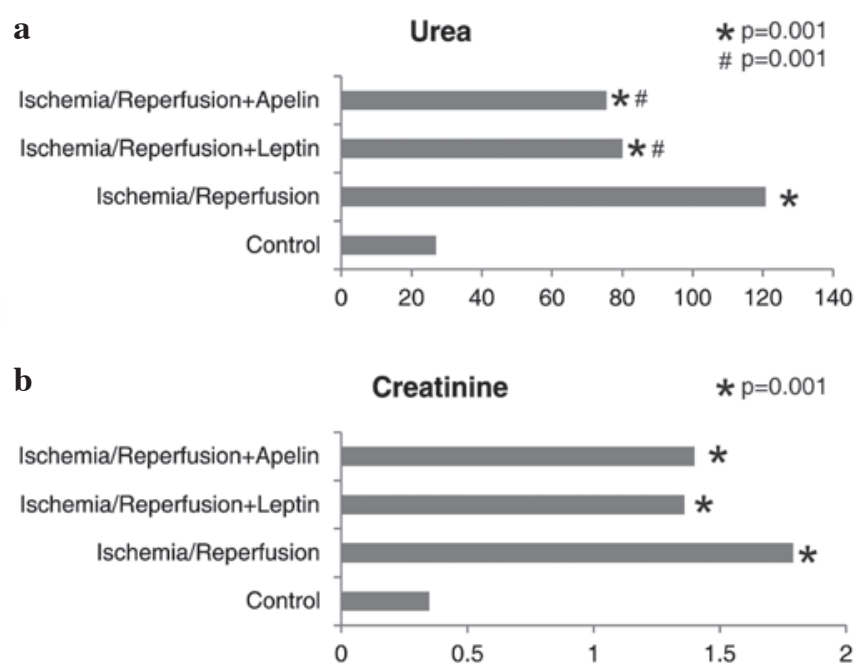

Figure 2. Comparison of the study groups in terms of (a) urea and (b) creatinine levels. "Different from the control group, ${ }^{\# D i f f e r e n t ~ f r o m ~ t h e ~ i s c h e m i a / ~}$ reperfusion group.

No significant differences were found between the study groups with respect to 24-hour urine protein, sodium, potassium, chloride, urea and urine density values. There were significant differences between the study groups in terms of GFR and DMSA uptake (Table II).

The urea level was significantly higher in the I/R group compared to the control, I/R+L and I/R+A groups. Urea levels of the $\mathrm{I} / \mathrm{R}+\mathrm{L}$ and the $\mathrm{I} / \mathrm{R}+\mathrm{A}$ groups were comparable, but were higher than that of the control and lower than that of the I/R group. Creatinine levels were higher in all three ischemic groups compared to the control group (Fig. 2).

Total protein levels were lower in the $\mathrm{I} / \mathrm{R}+\mathrm{L}$ and $\mathrm{I} / \mathrm{R}+\mathrm{A}$ groups compared to the control group. GGT levels were higher in all three ischemic groups compared to the control group. GGT levels of the I/R+L and I/R+A groups were comparable, but were significantly lower than that of the I/R group. ALT 
Table II. Laboratory analysis of the urine samples and dimercaptosuccinic acid uptake in the study groups.

\begin{tabular}{|c|c|c|c|c|c|}
\hline & Control & $\begin{array}{l}\text { Ischemia/reperfusion } \\
+ \text { leptin }\end{array}$ & $\begin{array}{c}\text { Ischemia/reperfusion } \\
+ \text { apelin }\end{array}$ & Ischemia/reperfusion & P-value \\
\hline 24-hour urine protein (mg/dl) & $114.00 \pm 11.86$ & $117.88 \pm 9.60$ & $117.63 \pm 9.86$ & $117.63 \pm 10.61$ & $>0.05$ \\
\hline 24-hour urine sodium (mmol/l) & $109.63 \pm 18.49$ & $110.50 \pm 20.78$ & $110.75 \pm 19.35$ & $124.12 \pm 44.46$ & $>0.05$ \\
\hline 24-hour urine potassium ( $\mathrm{mmol} / \mathrm{l})$ & $140.25 \pm 14.12$ & $140.13 \pm 13.80$ & $140.88 \pm 15.12$ & $141.38 \pm 13.84$ & $>0.05$ \\
\hline 24-hour urine chloride $(\mathrm{mmol} / \mathrm{l})$ & $127.38 \pm 15.76$ & $129.25 \pm 20.06$ & $129.50 \pm 19.15$ & $130.50 \pm 15.37$ & $>0.05$ \\
\hline 24-hour urine urea (mg/dl) & $1,013.75 \pm 6.94$ & $1,012.50 \pm 6.55$ & $1,010.63 \pm 6.23$ & $1,011.88 \pm 7.04$ & $>0.05$ \\
\hline Urine density & $7,568.75 \pm 481.77$ & $7,405.00 \pm 636.04$ & $7,405.00 \pm 634.58$ & $7,400.00 \pm 681.60$ & $>0.05$ \\
\hline $\begin{array}{l}\text { Glomerular filtration } \\
\text { rate }(\mathrm{ml} / \mathrm{min})\end{array}$ & $2.43 \pm 1.26^{\mathrm{b}}$ & $0.68 \pm 0.35^{\mathrm{a}}$ & $1.66 \pm 0.49$ & $1.71 \pm 0.34$ & 0.001 \\
\hline $\begin{array}{l}99 \mathrm{mTc} \text { dimercaptosuccinic } \\
\text { acid uptake }(\%)\end{array}$ & $33.30 \pm 11.06^{\mathrm{c}}$ & $18.37 \pm 8.50$ & $17.48 \pm 5.91^{\mathrm{a}}$ & $18.76 \pm 6.98$ & 0.03 \\
\hline
\end{tabular}

For each group, $\mathrm{n}=8$. Values are presented as mean $\pm \mathrm{SD}$. ${ }^{\mathrm{a}}$ Different from the control group, ${ }^{\mathrm{b}}$ Different from the ischemia/reperfusion group, ${ }^{\mathrm{c}} \mathrm{Different}$ from the ischemia/reperfusion + leptin group. P-value in bold print indicates a significant difference.
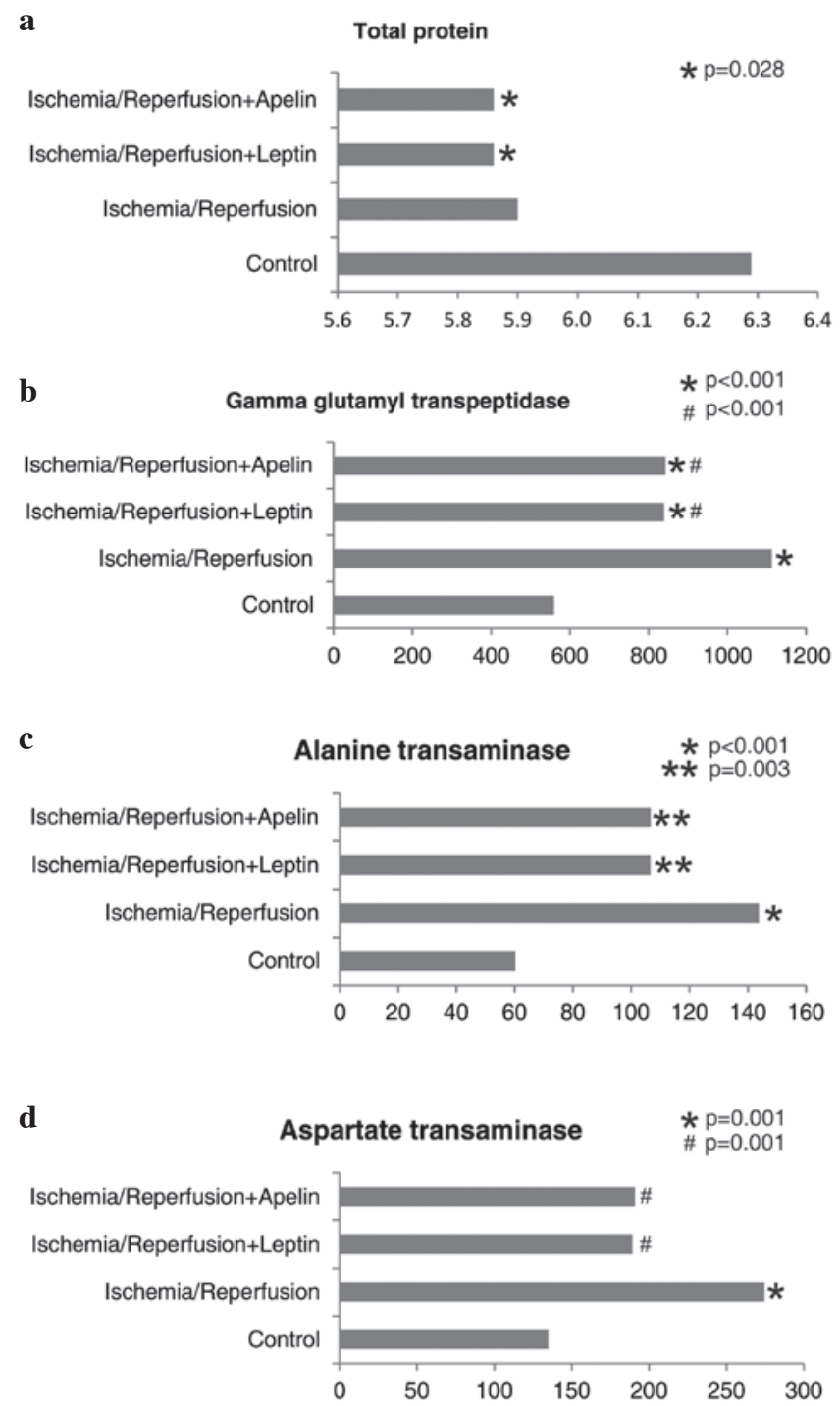

Figure 3. Comparison of the study groups in terms of (a) total protein, (b) $\gamma$-glutamyl transpeptidase, (c) alanine transaminase and (d) aspartate transaminase levels. ${ }^{*, * *}$ Different from the control group, ${ }^{\sharp}$ Different from the ischemia/reperfusion group.

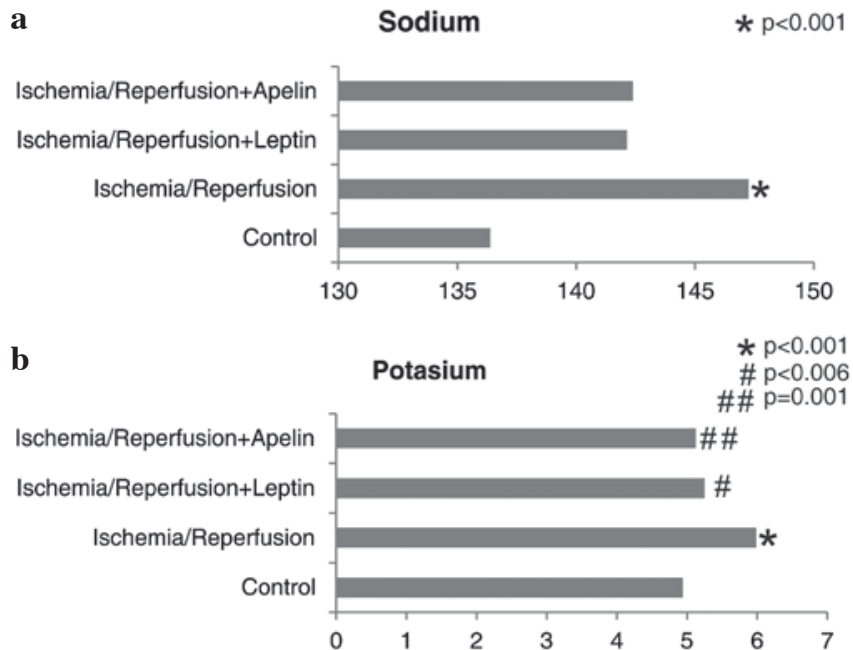

Figure 4. Comparison of the study groups in terms of (a) sodium and (b) potassium levels. "Different from the control group, $\#, \#$ Different from the ischemia/reperfusion group.

levels were higher in all three ischemic groups compared to the control group. The AST level of the I/R group was higher than that of the control group, while AST levels of the $\mathrm{I} / \mathrm{R}+\mathrm{L}$ and $\mathrm{I} / \mathrm{R}+\mathrm{A}$ groups were significantly lower than that of the $\mathrm{I} / \mathrm{R}$ group (Fig. 3).

Sodium and potassium levels were significantly higher in the I/R group compared to the control group. Potassium levels of the $\mathrm{I} / \mathrm{R}+\mathrm{L}$ and $\mathrm{I} / \mathrm{R}+\mathrm{A}$ groups were significantly lower than that of the I/R group (Fig. 4).

Glomerular filtration rate was markedly lower in the I/R group compared to the control group. GFR values of the $\mathrm{I} / \mathrm{R}+\mathrm{A}$ and $\mathrm{I} / \mathrm{R}+\mathrm{L}$ groups were not significantly, but numerically higher than that of the I/R group. GFR values of the control, $\mathrm{I} / \mathrm{R}+\mathrm{A}$ and $\mathrm{I} / \mathrm{R}+\mathrm{L}$ groups were comparable. DMSA uptake was lower in all three ischemic groups compared to the control group; however, only the difference between the $\mathrm{I} / \mathrm{R}+\mathrm{L}$ group and the control group reached a significance 
Table III. The degree of pathological damage in the study groups.

\begin{tabular}{lccccc}
\hline Renal damage (n) & $\begin{array}{c}\text { Control } \\
(\mathrm{n}=7)\end{array}$ & $\begin{array}{c}\text { Ischemia/reperfusion } \\
(\mathrm{n}=8)\end{array}$ & $\begin{array}{c}\text { Ischemia/reperfusion } \\
+ \text { leptin } \\
(\mathrm{n}=7)\end{array}$ & $\begin{array}{c}\text { Ischemia/reperfusion } \\
+ \text { apelin } \\
(\mathrm{n}=8)\end{array}$ & P-value \\
\hline None & 7 & 0 & 1 & 3 & $<0.001$ \\
Mild & 0 & 0 & 3 & 3 & \\
Moderate & 0 & 2 & 3 & 1 & \\
Severe & 0 & 6 & 1 & 0 & \\
\hline
\end{tabular}
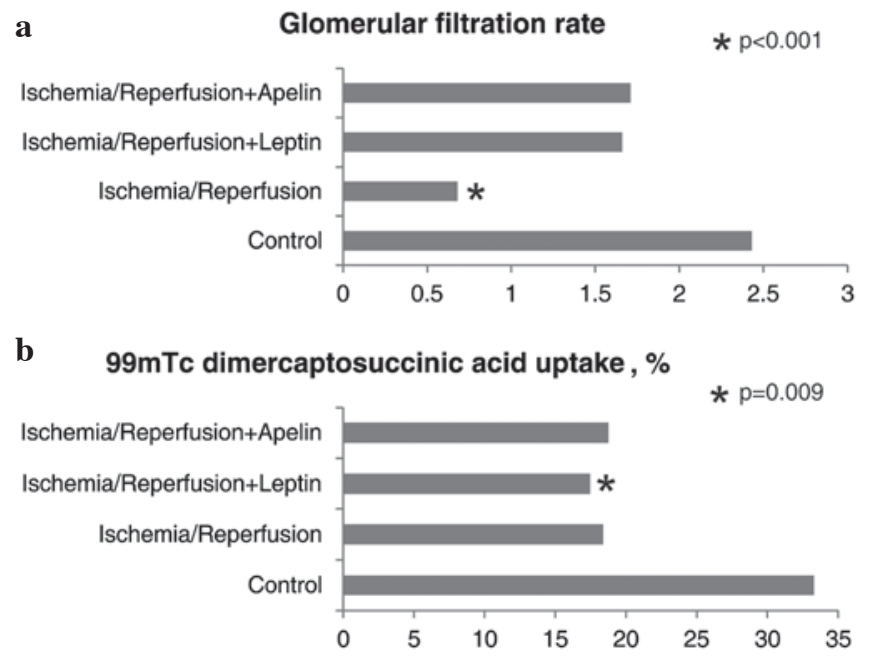

Figure 5. Comparison of the study groups in terms of (a) glomerular filtration rate and (b) dimercaptosuccinic acid uptake. "Different from the control group.

level (Fig. 5). There were significant differences between the study groups with respect to the degree of renal damage (Table III).

No pathological damage was observed in any of the animals in the control group. While two animals had moderate and six animals had severe renal damage in the I/R group, three animals had moderate and only one animal had severe renal damage in the $\mathrm{I} / \mathrm{R}+\mathrm{L}$ group. Although moderate damage was observed in one animal in the $\mathrm{I} / \mathrm{R}+\mathrm{A}$ group, none of the animals in this group had severe renal damage (Fig. 6).

\section{Discussion}

The main finding of the present study was that pre-operatively administered leptin and apelin had protective, functional and histopathological, effects against renal I/R injury. Functional protection against I/R injury was demonstrated through BUN, creatinine and GFR measurements, while histopathological protection was demonstrated through examination of the degree of pathological damage. Moreover, it was found that increments in the AST, GGT, sodium and potassium levels demonstrated in the I/R group were decreased in the I/R+A and $\mathrm{I} / \mathrm{R}+\mathrm{L}$ groups.

Tissue damage caused by ischemia is further increased with reperfusion, and $\mathrm{I} / \mathrm{R}$ injury occurs. This unfavorable effect of reperfusion is more pronounced when the ischemic period
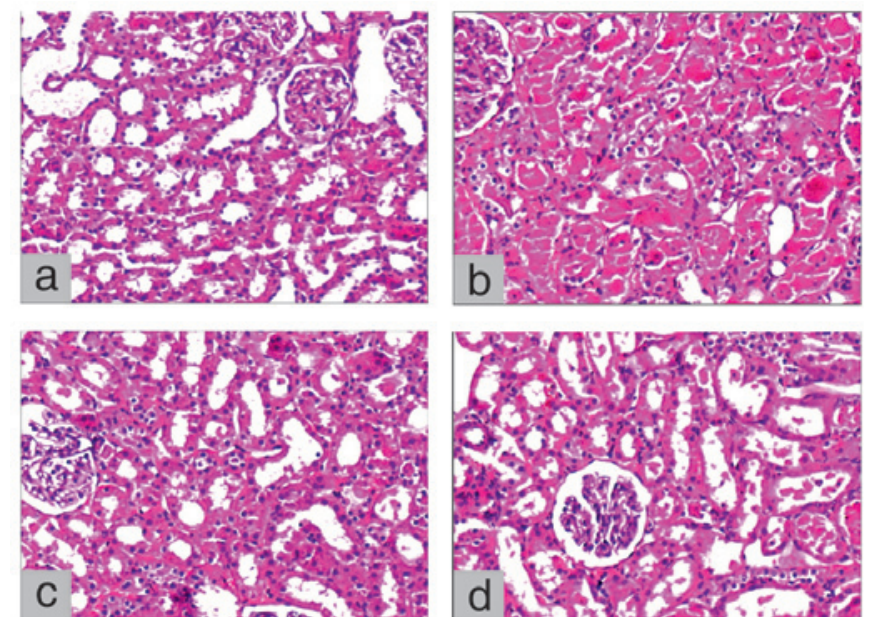

Figure 6. (a) Microscopy of the kidney demonstrating normal histology in the control group. (b) Histopathology of the kidney demonstrating extensive epithelial necrosis and hyaline cast formation in the I/R group. (c) Histopathology of the kidney demonstrating focal and mild epithelial necrosis and hyaline cast formation in the $\mathrm{I} / \mathrm{R}+\mathrm{A}$ group. (d) Histopathology of the kidney demonstrating moderate epithelial necrosis and hyaline cast formation in the $\mathrm{I} / \mathrm{R}+\mathrm{L}$ group. (a-d: H\&E, magnification, $\mathrm{x} 100)$.

is prolonged. Vascular endothelial cells, leukocytes, oxygen radicals, adhesion molecules and inflammatory mediators play a role in the complex pathophysiology of I/R injury (1). Reperfusion results in impaired endothelium-dependent dilation in arterioles, enhanced fluid filtration and leukocyte plugging in capillaries, and leukocyte trafficking and extravasation of plasma proteins in postcapillary venules. Production of oxygen radicals is increased in activated endothelial cells, and the balance between superoxide and nitric oxide is impaired, leading to the release of inflammatory mediators (e.g., platelet-activating factor, tumor necrosis factor). Moreover, synthesis of adhesion molecules, which mediate leukocyte-endothelial cell adhesion, is also increased (1).

Protective or therapeutic effects of a number of substances against renal I/R injury have been investigated using animal models in experimental studies. Improving effects of antioxidants, including phosphate ester of vitamin $\mathrm{C}$ and vitamin $\mathrm{E}$ (EPC-K1), edaravone (MCI-186), aminoguanidine, ascorbic acid, and stobadine, against renal I/R injury have been demonstrated in experimental studies employing rats and dogs $(2,14)$. Yamamoto et al (14) investigated the effects of EPC-K1 in a rat model of $\mathrm{I} / \mathrm{R}$ injury and histopathologically demonstrated that tissue damage was lower in rats receiving EPC-K1 prior to 
I/R compared to those that did not receive EPC-K1. Moreover, the mean tissue damage score for renal injury was significantly lower in the EPC-K1-treated group. BUN and creatinine levels measured to assess the renal function were significantly higher in the I/R group compared to the control group, while they were significantly decreased in the EPC-K1-treated group. Koga et al (15) reported that human atrial natriuretic peptide (hANP) was effective in the treatment of a number of types of $\mathrm{I} / \mathrm{R}$ injuries and that the renal protective effect of hANP could be associated with its antioxidant properties. In this particular study on rats, serum BUN and creatinine levels were demonstrated to be increased in the I/R group, but the increment was significantly inhibited in the hANP-treated group, and renal tissue damage was attenuated with hANP administration (15). In accordance with the two abovementioned studies, the present study also demonstrated that urea and creatinine levels were higher in the I/R group compared to the control group, but lower in the $\mathrm{I} / \mathrm{R}+\mathrm{A}$ and $\mathrm{I} / \mathrm{R}+\mathrm{L}$ groups compared to the $\mathrm{I} / \mathrm{R}$ group. These results indicate the protective effects of leptin and apelin against renal I/R injury. In a study by Medeiros et al investigating the effect of sildenafil on rat kidneys subjected to normothermic I/R (16), the protective effect of sildenafil was scintigraphically and histopathologically demonstrated. In the present study, the histopathologically protective effects of apelin and leptin against renal I/R injury were also demonstrated. While severe renal damage was found in six animals in the I/R group, only one animal had severe renal damage in the $\mathrm{I} / \mathrm{R}+\mathrm{L}$ group. No severe damage was observed in any of the rats in the $\mathrm{I} / \mathrm{R}+\mathrm{A}$ group. However, there was no significant difference between the $\mathrm{I} / \mathrm{R}, \mathrm{I} / \mathrm{R}+\mathrm{A}$ and $\mathrm{I} / \mathrm{R}+\mathrm{L}$ groups with respect to scintigraphic findings.

It has been reported that EPO reduces post-ischemic structural damage and preserves renal functions, particularly in male rats (17). Prókai et al (17) demonstrated via BUN and creatinine measurement and histopathological examination, that EPO had a protective effect against I/R injury. Lifor ${ }^{\circledR}$ is a novel artificial organ-preserving solution that comprises nutrients, growth factors and a non-protein oxygen and nutrient carrier. It was demonstrated in a rat model, via creatinine measurement and histopathological examination, that lifor solution reduced both warm renal I/R and cold storage injury, and that Lifor may provide protection against apoptosis (18). The protective effect of isoflurane preconditioning against renal I/R injury was demonstrated via urea and creatinine measurements and via histopathological examination in a study conducted on rats (19). In another study on rats, the beneficial effect of isoflurane plus remifentanil on the kidney was demonstrated via flow cytometry and serum creatinine levels (20).

The effects of apelin and leptin against I/R injury have been investigated in a number of animal models. The effect of apelin on the myocardium was investigated in vivo using a mouse model of I/R injury, and in vitro using the Langendorff-perfused isolated mouse heart model by measuring the infarct area. Moreover, the direct effects of apelin on rat cardiomyocytes were evaluated in vitro, and it was demonstrated that apelin protected the myocardium against I/R injury $(21,22)$. It has been reported that apelin plays a role in inflammation (23) and the pathophysiology of hepatic diseases (24), and that apelin level is predicted by the presence of coronary artery disease in kidney allograft recipients (25). It has been demonstrated that apelin plays a critical role in the development of a functional vascular network and that adipocyte-derived apelin is upregulated in case of hypoxia (26). In a study by Hacioglu et al (10), the protective effect of leptin against I/R injury in the small intestine of rats was demonstrated via tissue malondialdehyde and nitric oxide concentrations and histopathological examination. In another study employing a rat model of intestinal I/R injury, it was demonstrated via histopathological examination that pre-treatment with leptin prevented gut mucosal damage and improved intestinal rehabilitation (27). Expression of apelin receptor mRNA in all nephron segments in the rat kidney suggests that apelin has a modulatory effect on tubular function (28).

Urea and creatinine levels, which were examined in the majority of the abovementioned studies to assess the renal function, were also assessed in the present study. In addition, GFR values were evaluated. Similarly, as performed in the majority of the studies, histopathological examination was conducted to demonstrate tissue damage. Moreover, we compared the study groups via scintigraphic examination. Based on the findings that increased levels of urea and creatinine in the I/R group demonstrated a decrease in the $\mathrm{I} / \mathrm{R}+\mathrm{A}$ and $\mathrm{I} / \mathrm{R}+\mathrm{L}$ groups, while low GFR in the I/R group reached the control levels in the $\mathrm{I} / \mathrm{R}+\mathrm{A}$ and $\mathrm{I} / \mathrm{R}+\mathrm{L}$ groups, and that severe damage was observed in six animals in the $\mathrm{I} / \mathrm{R}$ group, one in the $\mathrm{I} / \mathrm{R}+\mathrm{L}$ group and none in the $\mathrm{I} / \mathrm{R}+\mathrm{A}$ group, it can be suggested that apelin and leptin have improving effects against renal I/R injury. It should be considered that the effects of leptin and apelin on experimental ischemic kidney might be different from those on the human kidney, and that the findings of the present study should be supported by clinical studies. Further experimental and clinical studies are warranted for an improved understanding of the effects of these substances in the pre-treatment of ischemic kidney and for the use of these substances in clinical practice. Currently, surgical procedures and organ transplantations have increased and become widespread. Thus, pharmacological approaches with proven clinical efficacy are required in order to prevent and treat renal I/R injury that might occur due to perioperative reasons.

\section{References}

1. Carden DL and Granger DN: Pathophysiology of ischaemia-reperfusion injury. J Pathol 190: 255-266, 2000.

2. Chatterjee PK: Novel pharmacological approaches to the treatment of renal ischemia-reperfusion injury: a comprehensive review. Naunyn Schmiedebergs Arch Pharmacol 376: 1-43, 2007.

3. Li MD: Leptin and beyond: an odyssey to the central control of body weight. Yale J Biol Med 84: 1-7, 2011.

4. Cao R, Brakenhielm E, Wahlestedt C, et al: Leptin induces vascular permeability and synergistically stimulates angiogenesis with FGF-2 and VEGF. Proc Natl Acad Sci USA 98: 6390-6395, 2001

5. Wolf G, Hamann A, Han DC, et al: Leptin stimulates proliferation and TGF-beta expression in renal glomerular endothelial cells: potential role in glomerulosclerosis. Kidney Int 56: 860-872, 1999.

6. Mastronardi CA, Yu WH and McCann SM: Resting and circadian release of nitric oxide is controlled by leptin in male rats. Proc Natl Acad Sci USA 99: 5721-5726, 2002.

7. Lin J, Yan GT, Wang LH, et al: Leptin fluctuates in intestinal ischemia-reperfusion injury as inflammatory cytokine. Peptides 25: 2187-2193, 2004.

8. Shi Y, Yan GT, Lin J, et al: Intestinal ischemia-reperfusion injury made leptin decreased. Regul Pept 133: 27-31, 2006. 
9. Kleinz MJ and Davenport AP: Emerging roles of apelin in biology and medicine. Pharmacol Ther 107: 198-211, 2005.

10. Hacioglu A, Algin C, Pasaoglu O, et al: Protective effect of leptin against ischemia-reperfusion injury in the rat small intestine. BMC Gastroenterol 5: 37, 2005.

11. Pan CS, Teng X, Zhang J, et al: Apelin antagonizes myocardial impairment in sepsis. J Card Fail 16: 609-617, 2010.

12. Kaya H, Balc1 TA, Cobaner A, et al: Evaluation on the renal tubular damage in rats with acute haemorrhagic hypovolemic shock using Tc-99m DMSA uptake scintigraphy. Turk J Nucl Med 12: 85-89, 2003.

13. Parra C, Salas P and Dominguez J: Effects of immunosuppressive drugs on rat renal ischemia reperfusion injury. Transplant Proc 42: 245-247, 2010

14. Yamamoto S, Hagiwara S, Hidaka S, et al: The antioxidant EPC-K1 attenuates renal ischemia-reperfusion injury in a rat model. Am J Nephrol 33: 485-490, 2011.

15. Koga H, Hagiwara S, Kusaka J, et al: Human atrial natriuretic peptide attenuates renal ischemia-reperfusion injury. J Surg Res: Nov 4, 2010. (Epub ahead of print)

16. Medeiros PJ, Villarim Neto A, Lima FP, et al: Effect of sildenafil in renal ischemia/reperfusion injury in rats. Acta Cir Bras 25: 490-495, 2010.

17. Prókai A, Fekete A, Bánki NF, et al: Renoprotective effect of erythropoietin in rats subjected to ischemia/reperfusion injury: gender differences. Surgery 150: 39-47, 2011.

18. Regner KR, Nilakantan V, Ryan RP, et al: Protective effect of Lifor solution in experimental renal ischemia-reperfusion injury. J Surg Res 164: 291-297, 2010.

19. Zhang L, Huang H, Cheng J, et al: Pre-treatment with isoflurane ameliorates renal ischemic-reperfusion injury in mice. Life Sci 88: 1102-1107, 2011.
20. Vianna PT, Castiglia YM, Braz JR, et al: Remifentanil, isoflurane, and preconditioning attenuate renal ischemia/reperfusion injury in rats. Transplant Proc 41: 4080-4082, 2009.

21. Simpkin JC, Yellon DM, Davidson SM, et al: Apelin-13 and apelin-36 exhibit direct cardioprotective activity against ischemia-reperfusion injury. Basic Res Cardiol 102: 518-528, 2007.

22. Zeng XJ,Zhang LK, Wang HX, et al: Apelin protects heart against ischemia/reperfusion injury in rat. Peptides 30: 1144-1152, 2009.

23. Malyszko J, Malyszko JS, Pawlak K, et al: Apelin, a novel adipocytokine, in relation to endothelial function and inflammation in kidney allograft recipients. Transplant Proc 40:3466-3469, 2008.

24. Kunduzova O, Alet N, Delesque-Touchard N, et al: Apelin/APJ signaling system: a potential link between adipose tissue and endothelial angiogenic processes. FASEB J 22: 4146-4153, 2008.

25. Malyszko J, Malyszko JS, Pawlak K, et al: Visfatin and apelin, new adipocytokines, and their relation to endothelial function in patients with chronic renal failure. Adv Med Sci 53: 32-36, 2008.

26. Principe A, Melgar-Lesmes P, Fernández-Varo G, et al: The hepatic apelin system: a new therapeutic target for liver disease. Hepatology 48: 1193-1201, 2008.

27. Sukhotnik I, Helou H, Lurie M, et al: The effect of leptin on intestinal recovery following ischemia-reperfusion injury in a rat. Pediatr Surg Int 23: 473-478, 2007.

28. Hus-Citharel A, Bouby N, Frugière A, et al: Effect of apelin on glomerular hemodynamic function in the rat kidney. Kidney Int 74: 486-494, 2008 